\title{
Peradaban Teks: \\ Konsep Penafsiran Al-Quran Syed Nuqaib Al-Attas Menghadapi Modernisasi
}

\author{
(Civilization of the Text: The Concept of Al-Quran Interpretation by Syed Naquib \\ Al-Attas in Facing Modernization)
}

\author{
D.I. Ansusa Putra, Zikwan \\ UIN Sulthan Thaha Saifuddin, Jambi, Indonesia \\ ansusa@uinjambi.ac.id, zikwan@uinjambi.ac.id
}

DOI: $10.29240 /$ alquds.v5i1.2211

Submitted: 2020-12-16 | Revised: 2021-03-09 | Accepted: 2021-04-06

\begin{abstract}
Syed Nuqaib al-Attas projected a civilization rooted in the Quran and Hadith texts which were motivated by the massive secularization of values in Muslim countries by offering the concept of al-Quran interpretation. This paper aims to compile the concept of al-Attas Quranic interpretation, which is still scattered in some of his works, by building the structure of ideas and worldviews of the concept that the author calls metalinguistic interpretation. This paper uses an interpretive discourse analysis method. This method constructs the discourse by al-Attas ideas in his works, especially on two themes: 1) Islamic civilization and 2) the interpretation of the Quran. This article concludes that al-Attas offers cross-disciplinary knowledge that integrates the text of the Quran with other perspectives, namely: philosophy, intellectual tasawwuf, linguistics, and metaphysics. These cross-disciplines will produce an authoritative reading of the Quranic text and serve as a foundation to build a civilization facing modernity with various terminological offers, such as Ta'dib, din, ikhtiyar, and Islam. Furthermore, this position makes al-Attas different from several other figures such as Nasr Hamid Abu Zayd and Jamaluddin al-Afghani in the same discourse
\end{abstract}

Keywords: Metalinguistic, Syed Nuqaib al-Attas, Islamic civilization

Abstrak. Syed Nuqaib al-Attas memproyeksikan peradaban yang bersumber dari teks
al-Quran dan Hadis yang dilatarbelakangi oleh masifnya sekularisasi nilai di Negara
Muslim dengan menawarkan konsep penafsiran al-Quran. Tulisan ini bertujuan untuk
mengkompilasikan konsep penafsiran al-Quran al-Attas yang masih tercecer di
beberapa karyanya dengan membangun struktur ide dan pandangan dunia konsep
penafsiran al-Quran yang penulis sebut dengan penafsiran metalinguistik. Tulisan ini
menggunakan metode analisis wacana secara interpretative. Yakni menginterpretasikan
dan mengkonstruksi wacana yang dibangun oleh al-Attas dalam karya-karyanya
khususnya mengenai dua tema: 1) peradaban Islam dan 2) penafsiran al-Quran. Artikel
ini menyimpulkan bahwa al-Attas menawarkan lintas disiplin ilmu yang 229 
mengintegrasikan teks al-Quran dengan perspektif lain, yaitu: Filsafat, Tasawwuf intelektual, linguistic dan metafisika. Lintas disiplin ilmu ini akan menghasilkan pembacaan teks al-Quran yang otoritatif dan dijadikan sebagai landasan dalam membangun peradaban dalam menghadapi modernitas dengan berbagai tawaran terminologis, seperti: Ta'dib, din, ikhtiyar, islam. Selanjutnya, posisi ini membuat alAttas berbeda dengan beberapa tokoh lain seperti Nasr Hamid Abu Zayd dan Jamaluddin al-Afghani dalam diskursus yang sama.

Keyword: Metalinguistik, Syed Nuqaib al-Attas, Peradaban Islam

\section{Pendahuluan}

Peradaban merupakan suatu identitas yang sangat luas dan komprehensif. Peradaban merupakan gambaran terluas dari budaya, yang teridentifikasi melalui unsur-unsur obyektif umum seperti bahasa, agama, sejarah, institusi, kebiasaan ataupun melalui identifikasi diri yang subyektif. ${ }^{1}$ Peradaban didefinisikan sebagai unsur-unsur obyektif bersama, seperti bahasa, sejarah, agama, adat istiadat, lembaga, dan identifikasi subjektif diri dari bangsa. Peradaban merujuk pada tingkat kebudayaan yang tinggi.

Saat ini, peradaban manusia berada pada peradaban yang maju yang ditopang dengan kemajuan ilmu pengetahuan, sains dan teknologi. Peradaban Barat menjadi pemimpin peradaban dunia yang menemui urgensitasnya pada awal abad 20 dengan menawarkan konsep Modernisasi.

Gerakan modernisasi yang telah dimulai pada abad ke-16 hingga abad ke-19 di seluruh dunia menggaungkan semangat dengan memperkenalkan peradaban modern yang didefinisikan oleh Barat. Kata modern berarti suatu kondisi yang maju dengan pengetahuan tanpa nilai-nilai agama. Karena agama dianggap dapat membuat peradaban menjadi mundur. Karena agama tidak sejalan dengan keilmuan dan prinsip modernitas. Meskipun demikian, modernitas dengan cepat menyebar di seluruh dunia termasuk di Negara-negara Islam. ${ }^{2}$ Bahkan beberapa sarjana muslim terlihat mengafirmasi modernitas Barat dengan melakukan pembacaan ulang terhadap pemikiran Islam tradisional. $\mathrm{Hal}$ ini menyebabkan gerakan modernisasi di tubuh umat Islam yang dipimpin oleh Muhammad Abduh dimulai dan menyebar ke berbagai Negara muslim.

${ }^{1}$ Samuel P. Huntington, 'The Clash of Civilizations?', in Conflict After the Cold War: Arguments on Causes of War and Peace, 2015 (https://doi.org/10.4324/9781003060963-50).

${ }^{2}$ Muhammad Syafiq Borhanuddin, 'The Impact of Modernity on Traditional Asian Worldviews', in Thinking Framework, ed. by Muhammad Zainy Usman (Kuala Lumpur: RZSCASIS, UTM, 2020). 
Akan tetapi peradaban modernisasi menghasilkan kontradiksi dan konflik bentuk baru dan ironi kemanusiaan. ${ }^{3}$ Modernisasi diyakini membuat peradaban manusia menjadi tidak seimbang dengan terjadinya krisis kemanusiaan, krisis ekonomi, krisis pangan. Selanjutnya, modernitas juga telah diyakini menjadi menyebab ketidakseimbangan peradaban Islam, dan kebanyakan Islam hanya menjadi objek gerakan modernisasi.

Salah satu pemikir muslim yang mengamati perkembangan peradaban Islam adalah Muhammad Syed Nuqaib al-Attas. Al-Attas menyebut modernisasi pada dasarnya adalah gerakan westernisasi, yaitu penanaman ide dan cara pandang Barat ke seluruh dunia. Termasuk di dalamnya, budaya, pendidikan, ekonomi, nilai-nilai, filsafat hidup, dll. Penawaran ini dilatarbelakangi oleh realitas kemunduran umat Islam dalam berbagai aspek kehidupan. Dalam pandangan Al-Attas, dengan perubahan zaman yang semakin pesat memunculkan masalah baru bagi umat Islam, yaitu pertumbuhan sains yang semakin tercampuri oleh budaya Barat. Sains dinilai mengikis nilai moral dan agama, sehingga bukan lagi sains yang mengikuti kebutuhan manusia melainkan manusia menyesuaikan diri dengan sains. ${ }^{4} \mathrm{Hal}$ ini menjadi perhatian Al-Attas untuk mengembalikan umat Islam dari kemunduran dalam berbagai aspek kehidupan dengan menjadikan peradaban Islam sebagai acuannya. Menurut AlAttas upaya mendasar yang bekaitan dengan lemahnya Islam dalam sistem kehidupan dapat diatasi dengan menyatukan pemahaman diantara sarjana muslim mengenai ide-ide dan konsep fundamental yang berkaitan dengan Islam dan peradaban.

Mayoritas sains modern saat ini beranggapan bahwa perubahan merupakan sesuatu yang mutlak terjadi. Sehingga dalam peradaban Barat memiliki prinsip "segala sesuatu itu berubah, kecuali perubahan itu sendiri". Oleh sebab itu Al-Attas mengatakan bahwa peradaban Barat "selalu berubah dan 'menjadi' (becoming) sesuatu yang tidak pernah terjadi "being" kecuali bahwa 'adanya' itu akan dan selalu 'menjadi' (becoming)". Akibatnya banyak negara dan institusi yang dipengaruhi semangat peradaban Barat. Bahkan pelajar, pekerja dari berbagai kalangan terus mengikuti dan beradaptasi dalam menghadapi perubahan.

3 Azarenko, Sergey A. 'Modernity: Transformation of System of Values and Its Anthropological Aspects', Журнал Сибирского Федерального Университета. Серия: Гуманитарныле Науки, 2013. 1867

${ }^{4}$ Syed Muhammad Naquib Al-Attas, 'Islam and Secularism' (Kuala Lumpur: ISTAC, 1993); Makhfira Nuryanti and Lukman Hakim, Pemikiran Islam Modern Syed Muhammad Naquib Al-Attas', Substantia: Jurnal Ilmu-Ilmu Ushuluddin, 2020 (https://doi.org/10.22373/substantia.v22i1.5531). 
Al-Attas mencoba untuk membuka cakrawala ide tentang pembangunan peradaban Islam yang dipahami dengan salah sebelumnya. Atas sumbangsihnya, Al-Attas mendapatkan penghargaan Iqbal Centenary Commemorative Medal untuk kontribusinya dalam pemikiran Islam tersebut ${ }^{5}$ dan telah melahirkan puluhan karya tulis berupa buku dan monograf yang beberapa diantara menjadi sumber utama dalam penelitian ini.

Banyak peneliti yang telah mengulas pemikiran al-Attas. Seperti Aris Widodo dalam artikelnya Syed Muhammad Naquib Al-Attas': Semantic Reading of Islam as Din. ${ }^{6}$ Widodo menampilkan konsep pemaknaan semantic al-Quran al-Attas dalam menggali makna terminologi fundamental agar mempunyai daya membangun peradaban. Sebagaimana kata 'Islam' yang secara eksplisit disebutkan dalam Al-Qur'an diketegorikan sebagai din. cara terbaik untuk mengidentifikasi ruang lingkup kata 'Islam' adalah dengan mempelajari fokus kata din melalui pendekatan semantic. Widodo hanya mengambil satu aspek saja dalam konsep penafsiran al-Attas yaitu pendekatan semantik/linguistik.

Farah Ahmed dalam An exploration of Naquib al-Attas' theory of Islamic education as ta'dib as an 'indigenous' educational philosophy (2016) mengeksplorasi pemaknaan ta'dib sebagai filsafat pendidikan murni dalam pendidikan Islam. Terminologi al-Attas tentang ta'dib merupakan pemaknaannya terhadap kata 'ta'dib' dalam al-Quran. Hanya saja Ahmed hanya berfokus untuk mencari muatan pendidikannya.

Hazan Dzilo dalam The concept of 'Islamization of knowledge' and its philosophical implications ${ }^{7}$ mengajukan sebuah pandangan bahwa islamisasi ilmu pengetahuan dalam kerangka al-Attas tidak merujuk kepada konteks sosial politik. Akan tetapi islamisasi merupakan usaha penyesuaian bentuk-bentuk pengetahuan tertentu ke dalam muatan keilmuan Islam. Dzilo berbicara dalam konteks paradigma ilmu pengetahuan yang digagas oleh al-Attas yang disebut dengan Islamisasi Keilmuan.

Seluruh artikel di atas hanya mengkaji satu aspek saja dari pemikiran alAttas. Sedangkan artikel ini lebih komprehensif dalam membangun kerangka pikir al-Attas. Metalinguistik merupakan sebuah pendekatan yang menggabungkan beberapa disiplin ilmu yang terkait dengan bahasa tersebut. Dalam hal ini adalah disiplin filsafat, sufistik, linguistic, dan metafisik. Artikel ini

${ }^{5}$ Muslem, 'Konsep Islamisasi Ilmu Pengetahuan Dan Penerapannya Dalam Pendidikan Islam (Studi Pemikiran Syed Muhammad Naquib Al-Attas)', Tazkiya Jurnal Pendidikan Islam, 2019.

${ }^{6}$ Aris Widodo, 'Syed Muhammad Naquib Al-Attas' Semantic Reading of Islam as Din', Al-Jami'ab: Journal of Islamic Studies, 2009 < https://doi.org/10.14421/ajis.2009.471.135-163>.

${ }^{7}$ Hasan Dzilo, 'The Concept of "Islamization of Knowledge" and Its Philosophical Implications', Islam and Christian-Muslim Relations, 2012 (https://doi.org/10.1080/09596410.2012.676779). 
di saat yang sama mengkaji pendapat, konsep, wawasan al-Attas tentang teks alQuran dan penafsirannya.

Artikel ini mencoba untuk merangkai konsep penafsiran oleh Al-Attas dari hasil pembacaan-pembacaannya terhadap terminologi al-Quran. Konsepkonsep itu dijelaskan secara terpisah oleh al-Attas dalam tema-tema tertentu. Seperti pembacaan makna Islam dalam al-Quran yang dijelaskan pada bukunya Islam and Secularism, pembacaan makna Din yang diuraikan pada bukunya Islam: Faham Agama dan Asas Akhlak yang merupakan terbitan kedua oleh IBFIM pada tahun 2013, sedangkan versi Melayunya berjudul Islab the Concept of Religion and the Foundation of Ethics and Morality, kemudian pembacaan makna Ta'dib yang dijelaskan pada bukunya berjudul Aims and the objectives of Islamic Education: Islamic Education Series, Dan pembacaan makna ikhtiyar dalam bukunya Prolegomena to the Metaphysics of Islam.

Artikel ini merupakan penelitian kepustakaan dengan analisis interpretative terhadap wacana yang diuraikan oleh Syed Nuqaib Al-Attas dalam menjelaskan 1) Peradaban Islam, 2) Penafsiran al-Quran. Artinya konsep penafsiran al-Attas dirangkum melalui produk pembacaannya tentang tema-tema tertentu dalam al-Quran sehingga dapat diketahui alur pikir dan kerangka pikir al-Attas dalam penafsiran al-Quran dan dapat dihasilkan konsep penafsiran alQuran al-Attas yang berbeda dan unik daripada penafsiran-penafsiran sarjana alQuran yang lain.

Adapun metode dalam penelitian ini yaitu kepustakaan (library research). Yang mana seluruh data dan penelitian merujuk kepada objek yang akan dibahas, yaiu pemikiran Syed Muhammad Nuqaib Al-Attas. Literatur didapatkan dari buku-buku yang dikarang oleh Syed Muhammad Nuqaib Al-Attas, serta jurnal-jurnal dan artikel sebagai sumber pendukung. Teknik pengumpulan data yaitu dengan menghimpun data-data yang berkaitan dengan penelitian ini, menelaah data yang telah terkumpul, kemudian analisis isi, yaitu menganalisis penafsiran dan pemikiran syed Muhammad Al-Attas.

Selain itu, artikel ini juga dihubungkan dengan ide besar al-Attas tentang konsepsi ideal sebuah peradaban dengan segala aspek yang mengitarinya seperti pendidikan, social keagamaan, ketatanegaraan, dan politik.

\section{Komponen Konsep Penafsiran Metalinguistik}

Syed Muhammad Nuqaib Al-Attas berupaya memahami teks Al-Qur'an dengan berbagai disiplin ilmu. Salah satu yang ia fokuskan yaitu menafsirkan teks Al-Qur'an dengan memahami dari segi makna bahasa serta memahami 
makna intuisi melalui proses iluminatif. Al-Attas membentuk konsep penafsiran dari beberapa kerangka ilmu seperti: Filsafat, sufistik, linguistic dan metafisika. ${ }^{8}$ Perpaduan empat disiplin ini yang penulis sebut dengan konsep tafsir metalinguistik. Tafsir metalinguistic berangkat dari pemahaman Al-Attas mengenai falsafah (filsafat), sufi (tasawuf), dan linguistic (bahasa). Dimana menurutnya, ada tiga ciri dalam bahasa Islam: pertama, memiliki akar kata; kedua, memiliki pola khusus dalam arti (sehingga menyebabkannya bisa difahami); ketiga, karakteristik. ${ }^{9}$

Masing-masing keilmuan memiliki kedalaman materi tersendiri yang disesuaikan dengan perannya dalam kerangka keilmuan al-Attas. keilmuan paling dalam adalah sufistik yang merupakan intelektual Islam paling inti dan menghubungkan aspek kemanusiaan dengan konsep ketuhanan. ${ }^{10}$ Kemudian, keilmuan inti berikutnya adalah metafisika. Menurut al-Attas, seluruh nilai dan etika kemanusiaan terefleksikan dari seperangkat pemahaman metafisika atau yang disebut weltanschauung. Keilmuan ini dapat didemonstrasikan dengan mengkaji filsafat, pendidikan dan ilmu sosiologi. ${ }^{11}$ Berikutnya, keilmuan filsafat, dimana al-Attas membedakan filsafat dan metafsika. Filsafat merupakan luaran metafisika yang merupakan manifestasi metafisika berupa aturan-aturan umum dan khusus dalam kehidupan manusia seperti aturan logika, akal sehat, common sense, etiket. Dan luaran terakhir adalah linguistik, al-Attas menekankan ilmu tafsir merupakan ilmu pertama dalam Islam karena sifat Bahasa yang saintifik khususnya Bahasa Arab. Linguistic Arab memiliki posisi yang sangat penting dalam keilmuan Islam dikarenakan ilmu luaran yang menghubungkan dengan keseluruhan susunan, tujuan, pengertian pandangan dan peradaban Islam. ${ }^{12}$ Keterkaitan antara keempat bidang ilmu tersebut dapat digambarkan padda gambar 1 berikut:

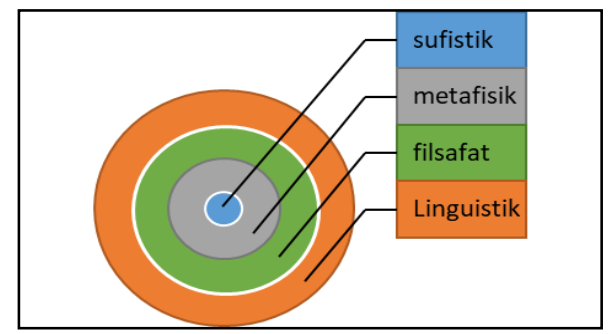

Gambar 1. Komponen Penafsiran Metalinguistik al-Attas

${ }^{8}$ Mohd Nor Wan Daud, Falsafah Dan Amalan Pendidikan Islam Syd M. Naquib Al-Attas Satu Huraian Konsep Asli Islamisasi (Kuala Lumpur: Penerbit Universiti Malaya, 2012).

${ }^{9}$ Naquib Al-Attas.

10 Syed Muhammad Naquib Al-Attas, Comments on the Re-Examination of Al-Raniri's Hujjatul Siddiq: A Refutation (Kuala Lumpur: Muzium Negara Malaysia, 1975).

${ }^{11}$ Mohd Nor Wan Daud, The Concept of Knowledge in Islam, ed. by Ziauddin Sardar (Mansell Islamic Studies, 1989).

12 Syed Muhammad Naquib Al-Attas, The Concept of Education In Islam: A Framework for an Islamic Philosophy of Education (ISTAC-UM, 1991). 
Tafsir metalinguistik terbentuk melalui empat komponen kerangka fikir: pertama, landasan sufistik Al-Attas banyak terpengaruh dengan aliran tasawmuf falsafi atau yang disebut sufi intelektual. Karena menurutnya tasawwuf Islam merupakan unsur terpenting dalam memperoleh ilmu yaitu konsep spiritual yang tidak terlepas dari kuasa Ilahiah. Al-Attas berpendapat Tasawwuf adalah Pengamalan syariat ditingkatan ibsan. ${ }^{13}$ Menurutnya tasawuf intelektual merupakan suatu disiplin yang terintegrasi untuk mengakses hakikat sesuatu dengan cara pemahaman akal dan pengamatan fenomenologi terhadap alam dengan dimensi transempirikal. Tasawuf melihat fenomena sebagai immaterial teacher. ${ }^{14}$

Al-Attas pada aspek ini memahami tasawuf melalui esensi dari sesuatu. Esensi yang jelas dengan bentuk dunia eksternal atau universal yang berkembang dengan intelektual ('AqD) dan syariat, atau pewahyuan mistik seperti penyingkapan (Kasyf) dan pengalaman langsung (zauq). ${ }^{15}$

Pengamatan terhadap fenomena-fenomena alam dengan dimensi transedental merupakan inti kewujudan akidah seorang muslim, di dalam tasawuf disebut ta'ayyun dan tajalli. Konsep ini membantu Islam untuk memahami hubungan interaksi tiga ruang lingkup keilmuan: ketuhanan, kemanusaan dan Alam ${ }^{16}$.

Penafsiran al-Quran menurut al-Attas merupakan manifestasi ayat Allah dalam bentuk teks dan Bahasa. Pembacaan terhadap ayat al-Quran harus dipahami melalui pembacaan iluminatif dengan berupaya mendapatkan cahaya ma'rifatullah. Agaknya, al-Attas mengkonfirmasi tasawuf al-Ghazali dengan konsep takhalli, tahalli, dan tajalli. ${ }^{17}$ Begitupula dengan pernyataan Al-Attas bahwa kewujudan manusia dibagi menjadi enam tingkatan, yaitu wujud hakiki (haqiqi), wujud indrawi (hissi), wujud khayalan (Khayali), wujud akal ('aqh), dan wujud metaforis (syibhi), yang menurutnya pada setiap tingkatan ini, persepsi manusia tentang objek-objek atau tingkat pemahaman manusia tidaklah sama ${ }^{18}$. Sebagaimana dalam memahami Al-Qur'an, sampainya ilmu dan pemahaman ke

${ }^{13}$ Daud, Falsafah Dan Amalan Pendidikan Islam Syd M. Naquib Al-Attas Satu Huraian Konsep Asli Islamisasi.

14 D.I Ansusa Putra, 'Epistemologi Tafsir Sufi Perspektif Esoterik-Fenomenologi', ULUL ALBAB Jurnal Studi Islam, 2018 < https://doi.org/10.18860/ua.v19i2.5019>.

15 Al-Attas, Comments on the Re-Examination of Al-Raniri's Hujjatul Siddiq: A Refutation.

${ }^{16}$ Akhmad Rofii Damyati, 'Syed Muhammad Naquib Al-Attas Dan Konsep Metafisik', EL-FURQONLA, Vol. 01.No.01 (2015), 18-31.

${ }^{17}$ Ramli Cibro, 'Semantik 'Irfāni Sebagai Model Tafsir Sufistik', Jurnal At-Tafkir, Vol. XII.No. 2 (2019), 187.

${ }^{18}$ Daud, Falsafah Dan Amalan Pendidikan Islam Syd M. Naquib Al-Attas Satu Huraian Konsep Asli Islamisasi. 
dalam jiwa pembacanya tergantung pada kesucian jiwa, kualitas spiritual, intelektual, dan akhlak mereka.

Kedua, metafisika. Al-Attas memposisikan metafisika sebagai induk dari worldview Islam. Tanpa metafisika, akan sulit untuk mengetahui pandangan dunia Islam yang sebenarnya. Al-Attas menjelaskan secara komprehensif mengenai metafisika Islam dalam bukunya Prolegomena to the Metaphysics of Islam: an Exposition of the Fundamental Elements of the Worldview, al-Attas menyebut bahwa konsep ilmu pengetahuan (teori maupun metode) pada setiap peradaban dibentuk berdasarkan kerangka fikir metafisika dan worlviewnya. ${ }^{19}$ Oleh sebab itu, membangun kerangka metafisika Islam merupakan salah satu usaha dalam membangun peradaban Islam. Pengetahuan tentang kerangka metafisika Islam diketahui melalui penafsiran atas sumber-sumber fundamental dalam peradaban Islam. Dalam hal ini sumber fundamental yang dimaksud adalah al-Quran dan Hadis. Karena, Al-Quran dan hadis merupakan sumber utama dalam mendefinisikan kebenaran dan realitas.

Pemahaman Al-Attas tentang metafisika berpijak pada pemahaman AlQur'an dan Sunnah Nabi Muhammad S.A.W., didasarkan pada kaidah tafsir dan takwil tradisional. Tafsir, menurutnya mesti berorientasi pada nilai-nilai objektifitas dan meminimalisir setiap subjektifitas mufassir.

Metafisika merupakan hakikat fundamental untuk mengetahui eksistensi dan realitas sesuatu yang tergambar pada fenomena-fenomena. ${ }^{20}$ Studi metafisika terpusat pada realitas yang dikaji. Kata metafisika biasanya merujuk kepada pemahaman atas isi pandangan terkait hal yang ada di balik fenomena fisikal. Metafisika merupakan bagian dari filsafat yang membicarakan wujud dan kewujudan. Saat ini metafisika tidak begitu populer dalam kancah pengetahuan modern. Adanya arus westernisasi atau berfikir ala barat membuat sikap meremehkan pentingnya metafisika dalam wacana peradaban Islam. Padahal metafisika yang didalamnya termasuk pembahasan teologis sangat penting dalam menggali konsep dasar sebuah paradigma.

Al-Attas menyatakan bahwa metafisika Islam tidak dibangun atas pandangan terhadap materi. Karena worldview Islam tidak berlandaskan spekulasi filosofis yang berasal dari data observasi melalui pengalaman yang terindra dan pengetahuan yang dapat dilihat. Akan tetapi, worldview Islam memandang bahwa kehidupan dunia mempunyai kaitan yang erat dengan aspek akhirat. Menurut alAttas, realitas tidak diartikan dengan waqa'i dalam bahasa Arab kontemporer yang mempunyai makna yang sama dengan makna realitas dalam konsepsi barat.

${ }^{19}$ Syed Muhammad Naquib Al-Attas, 'Prolegomena to the Metaphysics of Islam', Kuala Lumpur: International Institute of Islamic Thought and Civilization, 1995.

${ }^{20}$ Rizal Mustansyir, 'Aliran-Aliran Metafisika’, Filsafat, 1997. 
Akan tetapi, definisi realitas adalah hakekat (al-Haqiqab). Oleh sebab itu pandangan dunia Islam berarti perspektif Islam tentang kewujudan.

Visi Islam terhadap realitas dan kebenaran merupakan sebuah penelusuran metafisik terhadap dunia yang tampak dan yang tidak tampak termasuk perspektif terhadap kehidupan social secara keseluruhan. Secara historis diketahui bahwa ilmuan Islam klasik tidak terbagi atas aliran-aliran filsafat empiris, rasionalis, positivis, kritisis, dan lain-lain. ilmuan Islam secara individual melakukan metode transdisiplin dalam menginvestigasi keilmuan dan tidak mendikotomikan antara subjek ilmu dan objek ilmu. al-Attas sebutnya sebagai metode pengetahuan taubidic. ${ }^{21}$

Hal inilah yang membedakan antara peradaban Islam dengan peradaban lainnya. Menurutnya, metafisika peradaban Barat berbeda dengan metafisika Islam oleh sebab itu modernitas yang dikembangkan oleh Barat sesungguhnya mempunyai berbedaan akar metafisika dan worldview. Hal ini yang menyebabkan Al-Attas menolak modernitas yang terbukti memberikan problematika keilmuan dan social dalam peradaban Islam. Al-Attas menyebut bahwa tentunya kita tidak sepakat bahwa kebenaran, realitas, dan nilai yang berasal dari metafisika Islam dibangun atas paradigma relativitas dan pluralitas. Walaupun pemikiran kontemporer Muslim saat ini didominasi oleh paradigma empiris, hal itu dikarenakan pengaruh modernitas dan konsep westernisasi sekuler yang mendikotomikan antara sacred dan profane. Al-Attas memandang bahwa peradaban Barat dibangun atas koherensi buatan (artificial coherence). Koherensi buatan adalah hubungan yang tidak natural atau dengan kata lain tidak sesuai dengan fitrah. Dalam arti kata, hubungan yang dijadikan sebagai worldview yang berubah sesuai dengan perubahan keadaan. ${ }^{22}$ Perbedaan keduanya dapat dilihat melalui tabel 1 berikut ini:

\begin{tabular}{|l|l|l|}
\hline NO & \multicolumn{1}{|c|}{ ISLAM } & \multicolumn{1}{|c|}{ BARAT } \\
\hline $\mathbf{1 .}$ & $\begin{array}{l}\text { Metafisika menghasilkan } \\
\text { worldview }\end{array}$ & $\begin{array}{l}\text { Mengenyampingkan keberadaan } \\
\text { Metafisika dalam pengetahuan } \\
\text { dan keilmuan }\end{array}$ \\
\hline $\mathbf{2 .}$ & $\begin{array}{l}\text { Sumber kepada al-Quran dan } \\
\text { Hadis }\end{array}$ & $\begin{array}{l}\text { Bersumber pada pengalaman } \\
\text { empiris, rasio dan eksperimen }\end{array}$ \\
\hline $\mathbf{3 .}$ & Menggunakan Metode Taubidic & $\begin{array}{l}\text { Menggunakan metode yang } \\
\text { bermacam-macam tergantung }\end{array}$ \\
\hline
\end{tabular}

${ }^{21}$ Al-Attas, 'Prolegomena to the Metaphysics of Islam'.

22 Al-Attas, 'Prolegomena to the Metaphysics of Islam'. 


\begin{tabular}{|l|l|l|}
\hline & & $\begin{array}{l}\text { kecendrungan masing-masing } \\
\text { keilmuan }\end{array}$ \\
\hline 4. & $\begin{array}{l}\text { Berorientasi pada hakikat } \\
\text { kebenaran }\end{array}$ & Berorientasi pada perubahan \\
\hline
\end{tabular}

\section{Tabel 1: Perbedaan Karakter metafisika Islam dan Barat}

Ketiga, filsafat, filsafat al-Attas tidak menentukan satu aliran filsafat. Filsafat al-Attas dalam penafsirannya kembali kepada filsafat Islam klasik yang mempunyai karakteristik ensiklopedia dan taubidic. Hal ini berbeda dengan kebanyakan sarjana muslim periode modern yang banyak dipengaruhi oleh filsafat utilitarianism.

Adapun filsafat yang diaunut oleh Al-Attas banyak terinspirasi dari para filsuf ulama klasik seperti Al-Ghazali, Al-Farabi, Ibnu Sina dan yang lainnya. Meski demikian, Al-Attas tetap membangun pemikirannya sendiri yang tentu saja terdapat perbedaan dari para pemikir sebelumnya. Namun ia sejalan dengan para sarjana muslim sebelumnya yang menganggap ilmu pengetahuan sebagai sesuatu yang mungkin. Karakteristik corak filsafat al-Attas adalah penegasannya pada ontologi, epistemologi dan aksiologi ilmu untuk mengembalikan manusia kepada fitrahnya. Rumusan al-Attas tersebut merupakan dasar filosofis penafsiran al-Quran.

Filsafat Al-Attas mengarahkan konsep penafsiran Al-Quran untuk menemukan makna hakikat yang sebenarnya pada isi yang terkandung dalam AlQuran menurut kehendak Al-Quran itu sendiri. Dimana teks-teks Al-Quran memiliki hak-hak yang fundamental terhadap seluruh umat manusia khususnya umat muslim. Oleh karenanya memahami Al-Quran dengan metabahasa berfungsi agar sampai pada makna hakikat yang terkandung didalamnya

Menurut Kamus Besar Bahasa Indonesia (KBBI), otoritas artinya hak untuk bertindak, kekuasaan, wewenang. ${ }^{23}$ Tuhan, Al-Quran dan Nabi adalah pemegang otoritas dalam Islam, dan pada kenyataannya ketiganya merupakan pemegang otoritas yang sebenarnya. Al-Quran sebagai pemegang wewenang dalam mengatur tatanan hidup manusia. Eksistensi al-quran dan hadis dipandang sebagai otoritas tertinggi yang mengikat sehingga manusia tidak berada pada kekuatan otoritas kekuatan kemanusiaan lain selain Tuhan. ${ }^{24}$ Oleh sebab itu, pembacaan al-Quran berorientasi pada kebenaran mutlak sebagaimana termaktun dalam QS. al-Baqarah: 2. Al-Quran berhadapan dengan wewenang 2019

${ }^{23}$ E Setiawan, 'KBBI - Kamus Besar Bahasa Indonesia', Kamus Besar Bahasa Indonesia,

${ }^{24}$ Khaled M. Abou El Fadl, Speaking in God's Name: Islamic Law, Authority and Women, Oneworld Publications, 2014. 
intelektual manusia keperkasaannya mampu mengenyampingkan kehendak manusia. Karena manusia adalah makhluk dengan kewenangan dan kebenaran yang sangat terbatas. Maka keperkasaan al-Quran, dalam hal ini disebut dengan otoritas teks Al-Quran. Otoritas teks tidak hanya mencakup aspek instrinsik dari teks. Adapun motivasinya yaitu mengharap ridho Allah, merengkuh Tuhan, menemukan Tuhan, dan sebagainya. Sedangkan instrument dari praktik mood yaitu perasaan, emosi, dan lain sebagainya ${ }^{25}$. Orientasi filsafat dalam pandangan al-Attas dapat digambarkan pada gambar 2:

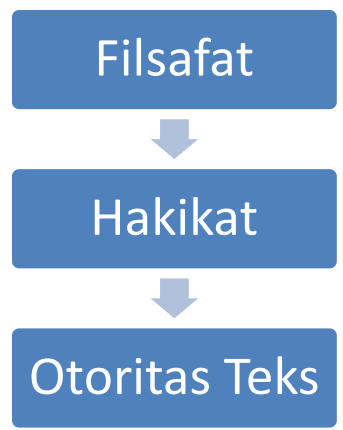

\section{Gambar 2. Filsafat Al-Attas dalam membentuk Otoritas Teks}

Dengan keberwenangan Al-Quran dalam mengatur tatanan hidup manusia, teks-teks Al-Quran disebut sebagai dasar dalam perkembangan peradaban. Islam dalam mencapai peradaban yang maju. Oleh karenanya peradaban dibangun di atas teks-teks Al-Quran tidak hanya bertujuan untuk membangun peradaban yang maju dan berkembang saja, tetapi secara bersamaan membentuk perilaku manusia yang bermoral dan memiliki etika dan estetika yang tinggi sehingga tercapai keseimbangan diantara keduanya.

Keempat, Muatan Linguistik Al-Quran merupakan elemen yang penting dalam membentuk penafsiran metalinguistik menurut al-Attas. ${ }^{26} \mathrm{Al}$-Quran merupakan kitab suci yang diturunkan dengan muatan Bahasa Arab dengan segala kompleksitasnya. Meskipun bahasa Arab dengan bahasa Al-Quran memiliki pola penuturan yang sama, namun makna yang terkandung dalam keduanya terdapat perbedaan. Karena Al-Quran merupakan kitab untuk seluruh umat manusia, maka segala pemahaman yang terkandung didalamnya telah mencapai nilai kebenaran yang sempurna. Kompleksitas bahasa al-Quran

${ }^{25}$ Subkhani Kusuma Dewi, 'Otoritas Teks Sebagai Pusat Dari Praktik Umat Islam', Jurnal Living Hadis, 2016 < https://doi.org/10.14421/living-hadis.2016.0101-09>.

${ }_{26}$ Daud, The Concept of Knowledge in Islam. 
dipersiapkan untuk menjadi pondasi pendirian peradaban manusia. ${ }^{27}$ Bahasa Arab yang terdapat dalam Al-Quran bukanlah bahasa Arab pada umumnya yang dipraktekkan pada peradaban Arab kontemporer. Sebab, al-Attas menyebut bahwa makna terminologi Arab kontemporer telah terkontaminasi dengan paradigma modernisme barat. Tentunya hal ini tidak terlepas bahwa tafsir dan takwil tradisional ini berpijak pada sifat ilmiah yang terdapat dalam bahasa Arab, yaitu sistem akar kata yang lengkap dengan arti dasar yang saling berkaitan, yang dapat menjaga makna kata-kata dan idenya dari perubahan sosial dan penafsiran subjektif. ${ }^{28}$

Bagi al-Attas kerangka linguistic Arab dibutuhkan dalam mendefinisikan terminology-terminologi al-Quran kepada makna hakikatnya. Penjelasan al-Attas tentang worldview mengungkapkan beberapa penafsirannya atas terminologyterminologi tertentu dalam al-Quran, seperti: hakikat, adab, hikmah, Al-Attas tidak merujuk makna terminology bahasa al-Quran kepada makna bahasa Arab kontemporer. Al-Attas mengusulkan pembacaan semantic dalam mencari makna dalam istilah-istilah al-Quran agar didapatkan makna hakikat dari terminology tertentu.

Mengembalikan terminologi-terminologi al-Quran tersebut kepada makna yang bermuatan worldview Islam merupakan salah satu factor penting Islamisasi Arab pada periode awal Islam. Hal ini dapat dibuktikan dengan keberadaan terminologi pra-Arab yang sudah terislamisasi setelah Islam. Ahli leksikologis Barat bahkan berpendapat bahwa Bahasa Arab mengalami perubahan mendasar setelah Islam datang yang pada akhirnya lambat laun menguasai peradaban dengan mengalahkan Persia dan Romawi. ${ }^{29}$

Kemunculan agama Islam menyaksikan proses Islamisasi bahasa Arab. ${ }^{30}$ Walaupun tidak mengubah makna dasar yang terdapat dalam kosakata bahasa Arab secara semantik, Islam telah melakukan penyusunan ulang atau bahkan transformasi yang radikal terhadap kosakata dan konsep inti yang terkandung dalam bahasa Arab agar sesuai dengan pandangan hidup Islam. Bagi Al-Attas bahasa Arab yang telah diislamkan inilah yang memiliki sifat ilmiah, yang mampu memuatkan kebenaran (truth) yang mutlak dan objektif ${ }^{31}$.

27 Achyar Zein, 'Urgensi Penafsiran Al-Qur'an Yang Bercorak Indonesia', MIQOT: Jurnal Ilmu-Ilmu Keislaman, 2016 (https://doi.org/10.30821/miqot.v36i1.105).

${ }^{28}$ Mohd Nor Wan Daud, Falsafah Dan Amalan Pendidikan Islam Syed M. Naquib Al-Attas: Satu Huraian Konsep Asli Islamisasi (Penerbit Universiti Malaya, 2005).

${ }^{29} \mathrm{Al}$-Attas, The Concept of Education In Islam: A Framework for an Islamic Pbilosophy of Education.

${ }^{30}$ Daud, Falsafah Dan Amalan Pendidikan Islam Syd M. Naquib Al-Attas Satu Huraian Konsep Asli Islamisasi.

31 Al-Attas, The Concept of Education In Islam: A Framework for an Islamic Philosophy of Education. 
Islamisasi terhadap bahasa Arab telah dilakukan sejak wahyu pertama kali diturunkan. Hal itulah yang kemudian mempengaruhi Islamisasi pemikiran dan akal. Islamisasi. Sebagai contoh pada kata "Allah", "Allah pada masa praislam atau masa sebelum Al-Quran diturunkan telah dipakai oleh bangsa Arab sebagai Tuhan yang paling tinggi. Mereka meyakini bahwa Allah yang mereka maksud merupakan tuhan pencipta alam semesta, penurun hujan, dan penjaga ka'bah. Hingga setelah Al-Quran diturunkan kata Allah beralih fungsi yang amat dahsyat, yang bukan hanya diyakini sebagai pencipta alam, penurun hujan, dan penjaga ka'bah saja, namun juga sebagai pengatur seluruh makhluk dan seluruh apa yang ada dalam kehidupan manusia. Nama Allah merupakan wujud dari semua sifat-sifat ketuhanan. ${ }^{32}$

Al-Attas menggunakan linguistik sebagai teori penafsiran kitab suci (theori of biblical exegesis) dan sebagai ilmu tentang pemahaman Bahasa (science off al linguistic understanding), tentu saja bahasa yang akan dikaji yaitu bahasa Arab, sebagaimana telah umum diketahui bahwa bahasa Al-Quran diturunkan dalam Bahasa Arab. Seperti yang dikemukakan oleh al-Attas bahwa bahasa Islam lahir seiring dengan proses turunnya wahyu kepada Rasulullah. Wahyu tersebut kemudian mengislamkan bahasa Arab Jahiliyah. Untuk itulah, menurutnya, istilah-istilah kunci (key terms) di dalam Islam pada akhirnya selalu bersumber dari Al-Quran. Sebab, al-Quran menjadi bukti paling sahih proses islamisasi bahasa Arab. Proses islamisasi Bahasa Arab menurut al-Attas dapat dilihat sebagai berikut:

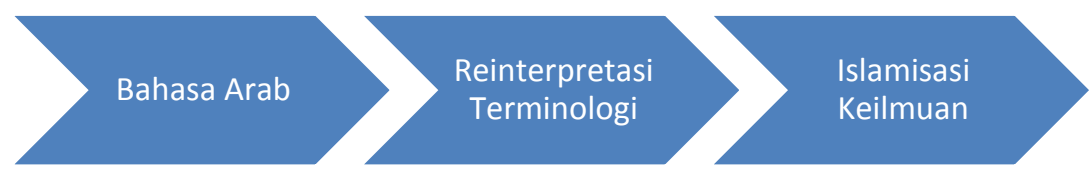

\section{Gambar 3. Proses Islamisasi Bahasa Arab}

Al-Attas menganggap ilmu linguistik dalam penafsiran al-Quran merupakan bagian ilmu yang sangat penting karena mengkaji tentang maknamakna yang terkandung dalam Al-Qur'an dan sunnah. Tentunya ilmu tafsir tidak lepas dari sifat ilmiah bahasa Arab yang dengan sifat ilmiahnya itu memberikan nilai universal pada ilmu pengetahuan yang diambil dari kedua sumber pokok Islam tersebut. ${ }^{33} \mathrm{Hal}$ ini terbukti bahwa bahasa Arab telah beberapa kali mengalami usaha perusakan, namun beberapa kali juga dan akan selalu bangkit

32 Toshihiko Izutsu, God and Man in The Qur'an: Semantics of The Qur'anic Weltanchaung (Petaling Jaya-Malaysia: Islamic Book Trust, 2008).

${ }_{33}$ Daud, Falsafah Dan Amalan Pendidikan Islam Syd M. Naquib Al-Attas Satu Huraian Konsep Asli Islamisasi. 
untuk memperbaiki kerusakan tersebut. ${ }^{34} \mathrm{Hal}$ ini bertujuan untuk menjaga keotentikan Al-Quran dan hadits Nabi. Bagi Al-Attas linguistik memiliki peran penting dalam konsep kaidah pendidikan dan peradaban, termasuk Islamisasi dalam berbagai cabang ilmu. Al-Attas juga mengungkapkan bahwa bahasa Arab tidak hanya bersifat estetis namun juga bersifat ilmiah. Seperti yang pernah beliau katakan:

"Jika berbicara tentang metodologi dan penerapan simbol-simbol linguistik secara benar, pertimbangan pertama kita adalah untuk memahami sifat ilmiah bahasa Arab, yang merupakan bahasa Islam serta alat untuk mengetengahkan pandangan Islam tentang realiti dan kebenaran. Yang saya maksudkan dengan kata "ilmiah" disini ialah aspek definitif yang menjadi ciri khas ilmu, sebab ilmu adalah definisi tentang realiti atau hakikat dalam pengertian had maupun rasm. ${ }^{35}$

Kemudian Al-Attas menegaskan bahwa saat ini yang bertumbuh dengan pesat adalah ilmu pengetahuan. Pemikiran Al-Attas berbeda dengan para pemikir pada zamannya, yaitu ia tidak hanya mempermasalahkan ilmu dengan kebodohan, yang dengan mudah dapat dibenarkan dengan proses pendidikan, dengan ilmu yang difahami dan disebarkan oleh peradaban Barat. Sebagaimana yang pernah ia katakan:

"Kita harus mengetahui dan menyadari bahwa sebenarnya ilmu pengetahuan tidak bersifat netral; bahwa setiap kebudayaan memiliki pemahaman yang berbeda-beda tentangnya, meskipun diantaranya terdapat persamaan. Antara Islam dan kebudayaan Barat terbentang pemahaman yang berbeda tentang ilmu, dan perbedaan itu begitu mendalam sehingga tidak dapat dipertemukan.”. ${ }^{36}$

\section{Dari Teks Menuju Peradaban}

Al-Quran berhasil mengislamkan bahasa Arab. Dan bersamaan dengan proses pengislaman tersebut, berlangsunglah pula pengislaman terhadap pemikiran dan peradaban. Adalah Syed M. Naquib Al-Attas, ulama yang menganggap sebuah peradaban dibangun atas dasar pengetahuan keislaman ${ }^{37}$. Baginya menghidupkan Kembali konsepsi ilmu menurut persfektif Islam, yang

${ }^{34}$ Naquib Al-Attas.

${ }^{35}$ Daud, Falsafah Dan Amalan Pendidikan Islam Syd M. Naquib Al-Attas Satu Huraian Konsep Asli Islamisasi.

${ }^{36}$ Daud, Falsafah Dan Amalan Pendidikan Islam Syd M. Naquib Al-Attas Satu Huraian Konsep Asli Islamisasi.

${ }^{37}$ Hamid Fahmi Zarkasyi, 'Reading Al-Attas' Analysis on God's Revalation as Scientific Methaphysics', Tsaqafah (https://doi.org/10.4108/eai.19-7-2019.2289500). 
diisi dengan sarat kerohanian, kemudian dari aspek kerohanian itu akan memunculkan sebuah peradaban yang luhur.

Al-Attas menganalogikan pandangan sufistiknya dalam proyeksi pembangunan peradaban Islam. Al-Attas menganjurkan untuk melakukan takhalli peradaban sebelum mengisinya dengan pengetahuan yang baru. Takhalli sendiri merupakan terminologi sufistik yang digagas oleh al-Ghazali. ${ }^{38}$ Melalui konsep takhalli, al-Attas memproyeksikan peradaban Islam yang kuat dengan menyucikan pemikiran yang menyimpang dalam peradaban. Penyimpangan yang dimaksud merujuk kepada pandangan sekularistik dan keilmuan dikotomis.

Selanjutnya, peradaban Islam diisi dengan nilai-nilai dan paradigma yang sesuai dengan metafisika Islam. Metafisika Islam tersebut digali dari al-Quran dan Hadis sehingga terbentuk pengetahun yang benar-benar otoritatif. Dalam hal ini, al-Attas telah menawarkan beberapa konsep metafisika. yaitu: konsep addien; konsep ihsan, konsep ikhtiyar; konsep pengetahuan ('ilm dan ma'rifah); konsep kearifan atau hikmah; konsep keadilan; konsep universitas. ${ }^{39}$ Dan kunci awal mengislamisasi peradaban menurut Al-Attas adalah dengan mengislamisasi bahasa. Selanjutnya, peradaban perlu diislamisasi dengan islamisasi Bahasa dan terminology. Langkah-langkah pembangunan peradaban al-Attas tersebut dapat digambarkan sebagaimana gambar 4 berikut:

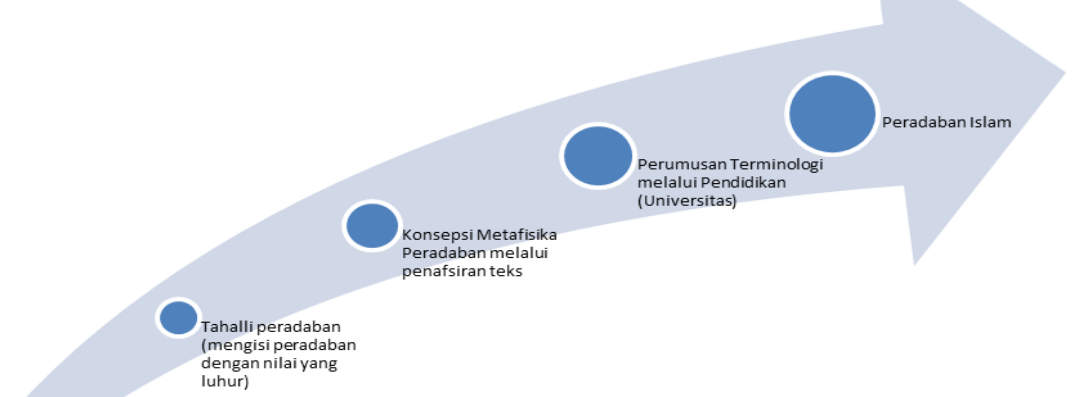

Takhalli

peradaban

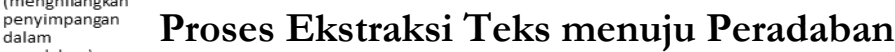

peradaban)

Gambar 4.

Hal inilah yang membuat Al-Attas mengemukakan dalam perbincangan tentang pendidikan Islam istilah $t a^{\prime} d i b$. Dengan demikian dapat menerapkan berbagai bidang ilmu pengetahuan. Sehingga akan menemukan tujuan yang

${ }^{38}$ Enung Asmaya, 'Hakikat Manusia Dalam Tasawuf Al-Ghazali', KOMUNIKA: Jurnal Dakwah Dan Komunikasi, 2018 (https://doi.org/10.24090/komunika.v12i1.1377).

${ }^{39}$ Daud, Falsafah Dan Amalan Pendidikan Islam Syed M. Naquib Al-Attas: Satu Huraian Konsep Asli Islamisasi. 
sebenarnya usaha dalam pencarian ilmu, yaitu agar dapat mencapai kebahagiaan dunia dan akhirat.

Selain ta'dib, Al-Attas berpendapat landasan dalam membangun peradaban Islam adalah dengan konsep ikhtiyar. Dalam tradisi Islam, "ikbtiyar" memiliki hubungan yang dekat dengan paham teologi dan filsafat Islam. Istilah ikhtiyar berasal dari bahasa Arab yaitu dari akar kata khara (khayara), Menurut Syed Muhammad Naquib Al-Attas, istilah ikhtiyar yang berarti "kebebasan" memiliki akar kata yang sama dengan 'khayr' yang berarti 'baik'. ${ }^{40}$ Oleh karena dalam ikbtiyar mengandung makna khair (baik). Pemahaman ini menutut seseorang untuk memilih sesuatu yang positif dan baik serta meperhatikan nilainilai kebaikan yang mengacu pada sumber hukum Islam, yaitu Al-Quran dan Hadits dengannya jalan apapun yang akan dipilih akan mendatangkan kebaikan pula.

Implementasi ikbtiyar dalam membangun peradaban yaitu manusia khususnya umat muslim mampu berusaha dengan memilih jalan yang dikehendakinya untuk memperoleh pencapaiannya, akan tetapi hal itu haruslah didasari dengan ilmu dan pengetahuan tentang nilai-nilai kebaikan dan sesuai dengan pedoman syariah. System syariah tidak hanya berpengaruh untuk menghasilkan sistem peradaban maju akan tetapi juga bertujuan untuk mencapai kehidupan yang baik dan seimbang. Sehingga mendatangkan kebaikan dan tidak ada kemudharatan bagi seluruh manusia.

Saat ini usaha yang dilakukan oleh mayoritas manusia dalam berbuat dan bekerja hanya sekedar mementingkan hasil yang akan diperoleh. Tanpa mempertimbangkan dimensi kebaikan di setiap aspek yang dilakukan. Sehingga seringkali perbuatan manusia dalam membangun peradaban itu hanya untuk memenuhi kebutuhan individu dan kelompok yang menghasilkan kehidupan yang tidak seimbang dan tidak harmonis.

Kemudian yang terakhir, Al-Attas mengarahkan proyeknya pada pembangunan peradaban yang dibangun atas dasar Islam. Yaitu dengan ajaranajaran Islam. Salah satu yang telah umum diketahui yaitu islamisasi ilmu. Ilmu merupakan langkah awal dalam membangun peradaban. ${ }^{41}$ Banyaknya sekolahsekolah hingga universitas-univesitas membuat ilmu semakin berkembang pesat dan faktor utama dalam membangun peradaban. namun, adanya arus westernisasi atau berfikir ala barat semakin mempengaruhi dunia pendidikan. Sehingga peradaban dibangun bukan atas dasar ajaran Islam, tetapi dibangun dengan mengkiblatkan dunia barat. Sehingga semakin berkembangnya peradaban, umat

40 Sakinah Fithriyah, 'Ikhtiyār Dalam Pemikiran Ekonomi Islam; Perspektif Teologi', Tasfiyah, 2020 (https://doi.org/10.21111/tasfiyah.v4i1.3966)

${ }^{41}$ Akhmad Rizqon Khamami, 'Membangun Peradaban Dengan Epistemologi Baru: $\begin{array}{lllll}\text { Membaca Pemikiran Said Nursi', } & \text { TSAQAFAH, } & 2015\end{array}$ (https://doi.org/10.21111/tsaqafah.v11i1.253). 
muslim semakin kehilangan identitas diri sebagai muslim dan semakin melupakan ajaran-ajaran Islam.

Saat ini Pendidikan menjadi mobilitas sosio-ekonomi individu atau negara. Hal ini sangat berbeda dari tujuan Pendidikan Islam. Dimana menurut Islam tujuan pendidikan yaiu mencari keridhaan Allah, menjadikan kejayaan individu dan kebahagiaan hidup di dunia dan akhirat. ${ }^{42}$ Menurutnya tujuan pendidikan adalah untuk mencetak generasi yang baik secara universal, yang mengarah kepada dua dimensi. Yaitu sebagai hamba Allah dan sebagai khalifah di muka bumi.

Meskipun tidak dapat dielakkan bahwa tujuan pendidikan adalah membangun dan mengembangkan kehidupan sosial dalam arti meningkatkan sosio-ekonomi suatu negara, akan tetapi hal itu tidak dapat dibiarkan begitu saja. Seharusnya pendidikan tidak menitikberatkan melatih pelajar untuk menjadi berbagai profesi sehingga mengabaikan pendidikan agama dan akhlak bagi pelajar. ${ }^{43}$ Dengan mengetahui ilmu-ilmu agama, maka manusia akan mengalami pertumbuhan dan perkembangan dalam spiritual sehingga membuatnya mengendalikan jiwa kebinatangannya. Begitu juga dengan tujuan akhir dalam universitas. Seharusnya tujuan akhirnya adalah mengembangkan spiritual pelajar setinggi-tingginya. Setiap universitas dan semua yang telibat di dalamnya haruslah mempehatikan visi dan misi dalam mengembangkan pengetahuan tentang keislaman, sehingga tercapailah tujuan tersebut. Idealnya setiap program tidak hanya dilihat dari segi keberkesanan dan peluang ekonomi, akan tetapi sebagai sarana agar teciptanya perkembangan optimal spiritual - intelektual para pelajar.

Sebagaimana di ISTAC (International Institut of Islamic and Civilization, Kuala Lumpur, merupakan Lembaga pendidikan tinggi yang digagas oleh Syed Nuqaib Al-Attas). Al-Attas membagi tiga bagian keilmuan yang saling berhubungan, yaitu Pemikiran Islam, Sains Islam, dan Tamadun Islam. Materi yang diajarkan pada Pemikiran Islam merupakan asas bagi materi yang akan diajarkan pada Sains dan Tamadun Islam karena keduanya saling bekaitan dengan pemikian Islam. Kursus ini merupakan kursus wajib di Lembaga Pendidikan tesebut. Adapun kursus wajib yang lainnya yaitu Sejarah dan Metodologi Penafsiran AL-Quran, Sejarah dan Metodologi Hadits, dan kursus tentang logika formal yang membahas para pemikir muslim. ${ }^{44}$

${ }^{42}$ Daud, Falsafah Dan Amalan Pendidikan Islam Syd M. Naquib Al-Attas Satu Huraian Konsep Asli Islamisasi.

${ }^{43}$ Daud, Falsafah Dan Amalan Pendidikan Islam Syd M. Naquib Al-Attas Satu Huraian Konsep Asli Islamisasi.

${ }^{44}$ Daud, Falsafah Dan Amalan Pendidikan Islam Syd M. Naquib Al-Attas Satu Huraian Konsep Asli Islamisasi. 
Kemudian Al-Attas mengkategorigan ilmu kepada dua bagan, yaitu Ilmu fadhu 'ain dan ilmu fardhu kifayah. Ilmu fardhu 'ain yaitu perwujudan dari dimensi universal, kekal, pribadi, dan spiritual yang mencakup ujuan Pendidikan dan kurikulum. Sedangkan ilmu fardu kifayah yaitu merealisasikan aspek-aspek particular, aspek yang berubah-rubah, aspek fisik dan sosial yang tercemin dalam lembaga Pendidikan dan seluruh kurikulum. ${ }^{45}$

Kurikulum-kuikulum tersebut seharusnya mampu berusaha melahirkan manusia yang baik yang puncaknya menjadi insan kamil. ${ }^{46}$ Yang mengerti dan mampu menjelaskan hakikat Tuhan, berilmu pengetahuan, mengerti tatanan hidup sebagai individu dengan masyarakat, serta mencapai kebahagiaan dunia dan akhirat.

\section{Kesimpulan}

Konsep penafsiran al-Quran yang dirumuskan oleh Syed Nuqaib al-Attas bertumpu pada pemaknaan teks al-Quran dengan menggunakan lintas disiplin ilmu, yaitu: Sufistik intelektual, metafisika, filsafat dan linguistic. Sehingga penulis menyimpulkan bahwa tafsir model ini merupakan tafsir meta-bahasa. Tafsir meta-bahasa berangkat dari pemahaman Al-Attas mengenai falsafah (filsafat), sufi (tasawuf), dan linguistic (bahasa). Konsepsi ini diaplikasikannya dalam berbagai kesempatan untuk membangun proyek peradaban Islam.

Al-Attas merekomendasikan untuk melaksanakan takhalli peradaban, yaitu usaha untuk mengosongkan peradaban Islam dari segala penyakit dan penyimpangan pengetahuan. Salah satu penyakit akut yang diidentifikasi oleh alAttas dalam menjelaskan proyeknya adalah sekularisasi, modernisasi, dan westernisasi negara-negara Muslim. Kemudian, langkah selanjutnya adalah dengan melaksanakan tahalli peradaban, yaitu mengisi peradaban dengan nilai, paradigma dan worldview berdasarkan kepada metafisika Islam. Pada proses ini peradaban membutuhkan re-interpretasi al-Quran dengan melahirkan terminologi-terminologi yang berasal dari al-Quran dan hadis. Salah satu instrument penting dalam re-interpretasi terminologi ini adalah perguruan tinggi (PT) dan pendidikan. Re-interpretasi ini berjalan dalam kerangka otoritas teks dengan menggunakan pendekatan lintas disiplin ilmu yang disebut metalinguistik. Adanya otoritas teks Al-Quran dalam mengatur tatanan hidup manusia, teks-teks Al-Quran disebut sebagai dasar dalam perkembangan peradaban. Kemudian peradaban akan menampakkan (tajalli) produk peradaban yang diinginkan sebagaimana dalam konsepsi Islam berorientasi pada keadilan, religiusitas, dan ikhtiyar.

${ }^{45}$ Wan Daud, The Educational Phylosophy and Practice of Syed Muhammad Naquib Al-Attas: An Exposition of The Original Concept of Islamization, (Kuala Lumpur: ISTAC, 1998), hal. 247-250.

${ }^{46}$ Ibid. 


\section{Bibliografi}

Al-Attas, Syed Muhammad Naquib, Comments on the Re-Examination of Al-Raniri's Hujjatul Siddiq: A Refutation (Kuala Lumpur: Muzium Negara Malaysia, 1975)

, 'Prolegomena to the Metaphysics of Islam', Kuala Lumpur: International Institute of Islamic Thought and Civilization, 1995

- The Concept of Education In Islam: A Framework for an Islamic Philosophy of Education (ISTAC-UM, 1991)

Asmaya, Enung, 'Hakikat Manusia Dalam Tasawuf Al-Ghazali', KOMUNIKA: Jurnal Dakwah Dan Komunikasi, 2018 <https://doi.org/10.24090/komunika.v12i1.1377>

Borhanuddin, Muhammad Syafiq, 'The Impact of Modernity on Traditional Asian Worldviews', in Thinking Framework, ed. by Muhammad Zainy Usman (Kuala Lumpur: RZS-CASIS, UTM, 2020)

Cibro, Ramli, 'Semantik 'Irfāni Sebagai Model Tafsir Sufistik', Jurnal At-Tafkir, Vol. XII.No. 2 (2019), 187

Damyati, Akhmad Rofii, 'Syed Muhammad Naquib Al-Attas Dan Konsep Metafisik', EL-FURQONLA, Vol. 01.No .01 (2015), 18-31

Daud, Mohd Nor Wan, Falsafab Dan Amalan Pendidikan Islam Syd M. Naquib AlAttas Satu Huraian Konsep Asli Islamisasi (Kuala Lumpur: Penerbit Universiti Malaya, 2012)

—, Falsafah Dan Amalan Pendidikan Islam Syed M. Naquib Al-Attas: Satu Huraian Konsep Asli Islamisasi (Penerbit Universiti Malaya, 2005)

— The Concept of Knowledge in Islam, ed. by Ziauddin Sardar (Mansell Islamic Studies, 1989)

Dewi, Subkhani Kusuma, 'Otoritas Teks Sebagai Pusat Dari Praktik Umat Islam', Jurnal Living Hadis, 2016 <https://doi.org/10.14421/livinghadis.2016.0101-09>

Dzilo, Hasan, "The Concept of "Islamization of Knowledge" and Its Philosophical Implications', Islam and Christian-Muslim Relations, 2012 $<$ https://doi.org/10.1080/09596410.2012.676779>

Fithriyah, Sakinah, 'Ikhtiyār Dalam Pemikiran Ekonomi Islam; Perspektif Teologi', Tasfiyah, $2020<$ https://doi.org/10.21111/tasfiyah.v4i1.3966>

Huntington, Samuel P., 'The Clash of Civilizations?', in Conflict After the Cold War: Arguments on Causes of War and Peace, 2015 
<https://doi.org/10.4324/9781003060963-50>

Khamami, Akhmad Rizqon, 'Membangun Peradaban Dengan Epistemologi Baru: Membaca Pemikiran Said Nursi', TSAQAFAH, 2015 <https://doi.org/10.21111/tsaqafah.v11i1.253>

M. Abou El Fadl, Khaled, Speaking in God's Name: Islamic Law, Authority and Women, Oneworld Publications, 2014

'Modernity: Transformation of System of Values and Its Anthropological Aspects', Журнал Сибирского Федерального Университета. Серия: Гуманитарные Науки, 2013

Muslem, 'Konsep Islamisasi Ilmu Pengetahuan Dan Penerapannya Dalam Pendidikan Islam (Studi Pemikiran Syed Muhammad Naquib Al-Attas)', Tazkiya Jurnal Pendidikan Islam, 2019

Mustansyir, Rizal, 'Aliran-Aliran Metafisika', Filsafat, 1997

Naquib Al-Attas, Syed Muhammad, 'Islam and Secularism' (Kuala Lumpur: ISTAC, 1993)

Nuryanti, Makhfira, and Lukman Hakim, 'Pemikiran Islam Modern Syed Muhammad Naquib Al-Attas', Substantia: Jurnal Ilmu-Imu Ushuluddin, 2020 $<$ https://doi.org/10.22373/substantia.v22i1.5531>

Putra, D.I Ansusa, 'Epistemologi Tafsir Sufi Perspektif EsoterikFenomenologI', ULUL ALBAB Jurnal Studi Islam, 2018 $<$ https://doi.org/10.18860/ua.v19i2.5019>

Setiawan, E, 'KBBI - Kamus Besar Bahasa Indonesia', Kamus Besar Bahasa Indonesia, 2019

Toshihiko Izutsu, God and Man in The Qur'an: Semantics of The Qur'anic Weltanchaung (Petaling Jaya-Malaysia: Islamic Book Trust, 2008)

Widodo, Aris, 'Syed Muhammad Naquib Al-Attas' Semantic Reading of Islam as Din', Al-Jami'ab: Journal of Islamic Studies, 2009 <https://doi.org/10.14421/ajis.2009.471.135-163>

Zarkasyi, Hamid Fahmi, 'Reading Al-Attas' Analysis on God's Revalation as Scientific Methaphysics', Tsaqafah <https://doi.org/10.4108/eai.19-72019.2289500>

Zein, Achyar, 'Urgensi Penafsiran Al-Qur'an Yang Bercorak Indonesia', MIQOT: Jurnal Ilmu-Ilmu Keislaman, 2016 $<$ https://doi.org/10.30821/miqot.v36i1.105> 